\title{
Small Intestinal Hamartoma
}

National Cancer Institute

\section{Source}

National Cancer Institute. Small Intestinal Hamartoma. NCI Thesaurus. Code C36206.

A non-neoplastic, hamartomatous polyp that arises from the small intestine. It includes the juvenile polyp and Peutz-Jeghers polyp. 